\title{
Ophthalmic findings in linear scleroderma manifesting as facial en coup de sabre
}

\author{
Hans Callø Fledelius ${ }^{1} \cdot$ Patricia Louise Danielsen ${ }^{2} \cdot$ Susanne Ullman $^{2}$ \\ Received: 12 October 2015 / Revised: 15 May 2018 / Accepted: 18 May 2018 / Published online: 4 July 2018 \\ (c) The Royal College of Ophthalmologists 2018
}

\begin{abstract}
Background To evaluate ophthalmic involvement in a long-term series of patients with en coup de sabre (ECS) close to the eye based on the hypothesis that this is not commonly affected, or simply under-reported.

Methods An observational study of ophthalmological findings in patients from Copenhagen University Dermatology Clinics. A standard eye examination further included exophthalmometry, axial length and keratometry (IOLMaster), and horizontal eye muscle thickness (B-scan ultrasonography).

Results Thirty-one consecutive patients were included from 2014 to 2015 (25 females, 6 males; median age, 33 years; range, 11-71 years). Twenty-seven patients had undergone ophthalmic evaluation more than once (observation time, 1-31 years; median, 7 years). Most eyes were normal or had currently adapted to eventual adnexal lesions and to insidious changes in eye position and/or motility. However, significant ipsilateral complications had developed related to 8 eyes, where two patients had more than one disorder. The ophthalmic pathologies were: blind eye $(n=2)$ due to adult age keratopathy/ perforation and to Coats-like retinal detachment in childhood; restricted eye motility and diplopia $(n=2)$; acquired corneal astigmatism $(n=2)$; and dense cataract with light sense only $(n=1)$. Two patients had optic neuritis-like presentations, and lacrimal sac pathology occurred in one.

Conclusions The main ophthalmic focus possibly explained the high proportion of significant lesions in this patient series (in 8 of 31). In addition to the established feature of enophthalmos, the oculometric evidence suggested smaller eye and rectus muscle involvement, interpreted as a secondary (late) negative trophic effect of the overlying skin disorder on eye structures.
\end{abstract}

\section{Introduction}

Localized scleroderma or morphea is a connective tissue disorder of unknown origin manifesting as skin lesions. Linear scleroderma is a distinct clinical subtype of localized scleroderma that may affect the face causing skin pigmentation, alopecia, fibrosis, loss of subcutis and atrophy of underlying tissue, including bone. When the target zones are the frontoparietal scalp and paramedian forehead, the term en coup de sabre (ECS) is used, referring to the resemblance with a stroke from a sword [1]. Diagnosis is clinical [1, 2]. Idiopathic

Patricia Louise Danielsen

patriciadanielsen@yahoo.dk

1 Copenhagen University Department of Ophthalmology, Rigshospitalet, Copenhagen, Denmark

2 Copenhagen University Department of Dermato-Venerology, Bispebjerg Hospital, Copenhagen, Denmark hemifacial atrophy or Parry-Romberg syndrome is hemifacial atrophy of the face mainly below the forehead. Patients with a combination of ECS and ipsilateral hemifacial atrophy have been described [3]. The relationship between these conditions is not clear [2, 3]. Clinical onset is usually in the first two decades but may occur later. ECS may involve the eyebrows and eyelashes (Fig. 1) but the adjacent neuroectodermal and neural crest-derived tissues of the orbit, including the eye, are usually spared. Prominent episcleral vessels and uveitis occur occasionally; however, eye function usually remains intact.

Occasional case reports on ECS have presented data on external eye muscles (diplopia) and/or inflammatory changes (episcleritis, uveitis) [4-10]. Central nervous system involvement has also been discussed [11-14].

\section{Methods}

Institutional review board approval was obtained for this study (H-3-2014-042(14)) and it followed the guidelines of 

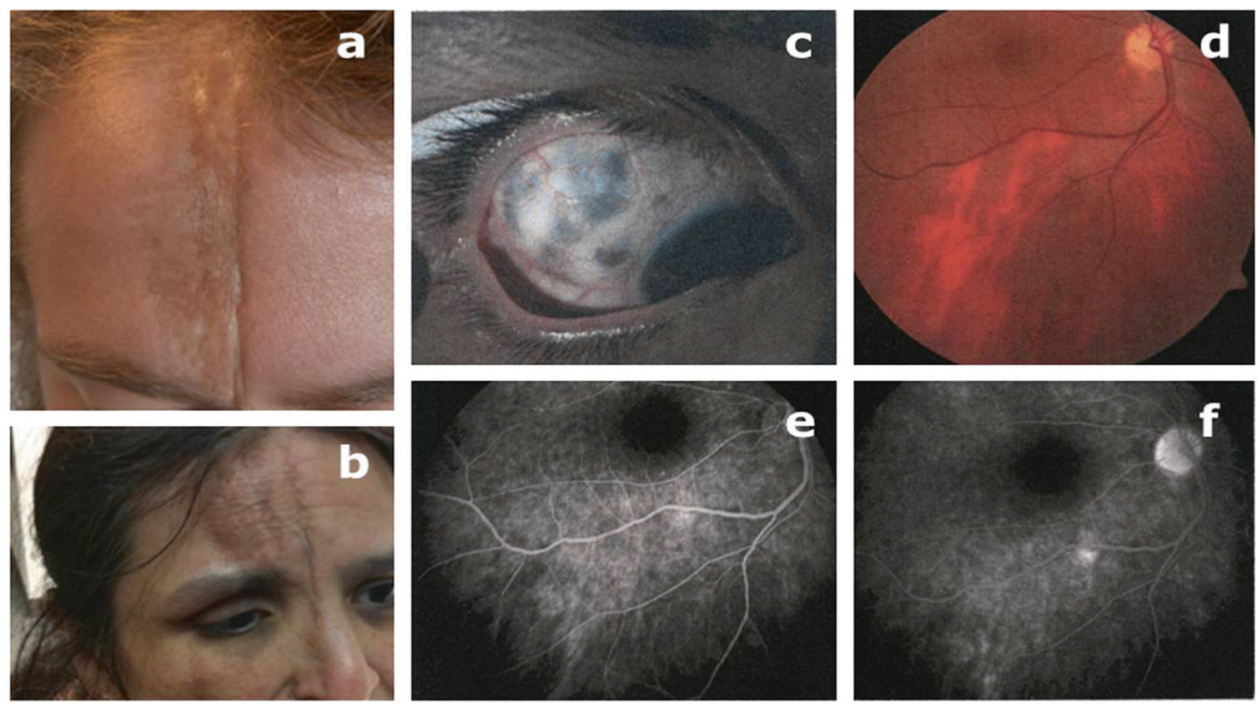

Fig. 1 Top: a clear case of linear coup de sabre, from the redressed hairline to the unaffected upper eye brow on the right side, and no ocular involvement (a). Patient with alopecia and three frontal sable cut lines continuing past the right medial canthus to (no shown) nares, chin and jaw. There is a 5-mm relative enophthalmus, oculomotor deficits, induced astigmatism, scleromalacia and recently (at age 47) also a dense cataract (b). Scleromalacia in same patient (c), right eye fundus with patchy, mainly vertical posterior pole hypopigmentations (d), with late hyperfluorescence on fluorescence angiograms (e), partly with a window effect (f).

the Declaration of Helsinki. The medical records for consecutive patients with ECS as diagnosed by a dermatologist at the Copenhagen University Department of Dermatology, Denmark, from 1974 to 2014 were reviewed. Only patients with ECS as defined by linear scleroderma mainly involving the frontoparietal scalp or medial or paramedial foreheadwith or without extension upwards into the scalp-or downwards affecting nasal sidewall, orbital and maxillary areas were included in the study. After receiving oral and written information, patients gave their written consent to participate.

Collected data included gender, age at onset of symptoms, previous diagnoses and any previous treatments. Clinical examination included full dermatologic and eye evaluation. Data were observational, and the present analysis focused on the possible effects of the facial ECS lesion on adjacent ophthalmic structures, with special regard to impaired function (visual parameters and eye motility) as based on updated ophthalmic evaluations. The examinations were performed 2014-2015 and comprised the following:

- History of ocular complaints

- By inspection: eye lid/aperture (a)symmetry; status of the eye brows and eye lashes; gross description of the chin, nose and mouth/teeth, when affected

- Hertel exophthalmometry (sagittal corneal position in relation to the lateral orbital margin, in millimetres)

- NIDEK autokeratorefractometry (2500, Aichi, Japan): refraction (in dioptres), keratometry, as the radius of the corneal curvature $\left(C_{\mathrm{rad}}\right.$, in millimetre) and as guidance for best corrected visual acuity (BCVA) by subjectively confirmed refraction (spherical equivalent: sphere + half cylinder)

- Ishihara test for colour vision and Pelli Robson chart for contrast sensitivity

- Kinetic Goldmann perimetry using standard objects $\mathrm{IV}, 4 \mathrm{e}$ and I,4e

- Slit lamp examination and direct ophthalmoscopy

- IOLMaster (Carl Zeiss Meditec AG, Jena, Germany) infrared interferometry (ocular axial length, in millimetres; keratometry, cylinder and $C_{\text {rad }}$, in millimetres, in the main meridians; with no general astigmatic trend associated with the linear skin disorder; single eye average $C_{\text {rad }}$ values were used in the calculations)

- Ultrasonic B-scan (NIDEK US-2500, Aichi, Japan) sonic texture and dimensions of the orbital contents, as a standard including the four horizontal eye muscles, the lateral and medial recti)

The main analyses evaluated the difference between the parameters for the affected and healthy side $(\mathrm{A} / \mathrm{H})$, also taking into account natural or inherent differences. Adolescent and adult population anisometropia, for instance, is usually idiopathic, early and permanent, thus differing from ECS cases possibly with eventual refractive change related to adjacent extra-ocular pathology [13-15]. Individual changes could further be outlined, also to include an evaluation of recorded onset age. Thus, the data also allowed assessment of possible changes over time. 
Data handling and two-tailed statistical evaluations were performed with the GraphPad 6 Prism programme. Normal or marginally normal distributions held for the $\mathrm{A} / \mathrm{H}$ analyses under study, as tested by d'Agostino \& Spearman and Kolmogorov-Smirnov tests, and parametric statistics in the principle could be used. However, non-parametric procedures were regarded a safer choice for the paired data, Wilcoxon's matched pairs test in particular and $\chi^{2}$ and sign tests were used when comparing distributions.

\section{Results}

Thirty-one patients with long-standing ECS (25 females, 6 males; age range, 11-71 years; median age, 33 years) were included. Twenty patients had ECS; in eight of these patients the linear affections extended down to the nostril, and a few also included the jaw. Nine patients had ECS and hemifacial atrophy. The last two patients had hemifacial atrophy without typical ECS, but were kept in the series due to their marked involvement of the ophthalmic region. Twenty-two patients had right-sided lesions, and nine had lesions on the left side $\left(\chi^{2}\right.$, side preference n.s.). Onset of skin lesions occurred at age $\leq 10$ years in 15 patients, in the second decade in 8 patients, the third decade in 3 patients, and at age 32-57 years in 5 patients.

Seven patients had positive antinuclear antibodies, all in low titres with different patterns. None fulfilled the criteria of the American Rheumatic Association for systemic scleroderma. In particular, none were positive for the specific anticentromere antibodies and Scl-70.

The median ophthalmic observation time was 7 years (range, $1-31$ years; $n=27$ ). Four patients were seen only once. Eleven patients had ophthalmic follow-up of more than 10 years. Thus, the data also allowed assessment of possible changes over time.

\section{Refraction}

Forty-six eyes with right/left symmetry had spherical equivalent refraction ranging between $-1 \mathrm{D}$ and $+1 \mathrm{D}$, of which 28 eyes even had narrow emmetropia (within \pm 0.25 D). Three patients had bilateral low myopia (between -1.25 $\mathrm{D}$ and $-2.25 \mathrm{D})$ and two had high myopia $(-8.75 /-9 \mathrm{D}$ and $-15 /-13 \mathrm{D}$, respectively). Only four of the remainder, all hyperopes, had values $\geq+3 \mathrm{D}$; two were female, one with $+3 /+4 \mathrm{D}$, the other with $+7.25 /+4.25 \mathrm{D}$. Amblyopia in the latter case was ascribed to basic anisometropia, and not to the scleroderma. Excluding these two cases, the $\mathrm{A} / \mathrm{H}$ refractive differences (not significant) clustered around 0 , which was also the median value (range, -0.79 to $1.5 \mathrm{D})$.

\section{Astigmatism}

At subjective trial only two patients accepted cylinders above 1 D. Individual recordings were generally symmetrical and with no $\mathrm{A} / \mathrm{H}$ difference. However, three patients showed keratometric asymmetry, with astigmatism evident on the affected side. One such male patient had a documented change from normal keratometry as recorded 11 years earlier (patient 2, Table 1), and a female had doubling of her cylinder value over 10 years (patient 3 , Table 1). The development in both was hypothesized as due to corneal changes, though without slit-lamp evidence. A third unilateral case occurred in a male, who was seen only once, with an ipsilateral $1.75 \mathrm{D}$ cylinder value.

\section{Visual parameters (BCVA, colour testing, contrast sensitivity)}

Three patients had moderate reduction (BCVA 0.5) to severe monocular visual loss (dense cataract and light sense only in patient 3 , and complete inflammatory loss of vision in patient 6) associated to the scleroderma, as specified in Table 1. Two patients had reversible vision loss on the diseased side, with features reminding of optic neuritis (patients 4 and 5), however with no subsequent relapses of visual loss. In another three patients, the side difference in visual acuity was ascribed to childhood amblyopia. Normal BCVA (0.8-1.3, decimal acuity, right and left eye median values 1.2 and 1.25) was recorded in a total of 45 eyes and statistically with no groupwise indication of an $\mathrm{A} / \mathrm{H}$ influence.

In addition to the above cases, a mention of another four patients with reduced vision ipsilaterally. A female with quiet childhood ECS lost vision as a result of dry eye from the age of 54 years, with stromal melting of the cornea and spontaneous perforation. Eventually, she had enucleation for blind painful eye. Her other eye also had significant dry eye features, but retained good vision. A definitive Sjögren diagnosis could not be established, and her overall clinical appearance was so mixed that we did not include her in Table 1. This also held for the following three cases: A 58year-old female with amblyopia since childhood who had drainage surgery for adult age nasolacrimal duct stenosis. A 13-year-old girl followed over 4 years for a white scarlike peripheral dot occasionally discovered on a routine OCTOS fundus photo. The sample's only case of excessive myopia was of juvenile onset, and with no association with adult age linear scleroderma (onset age, 38 years). Nor was the skin disorder held responsible for her bilateral cataracts; surgery at age 58 years redressed BCVA to normal. 


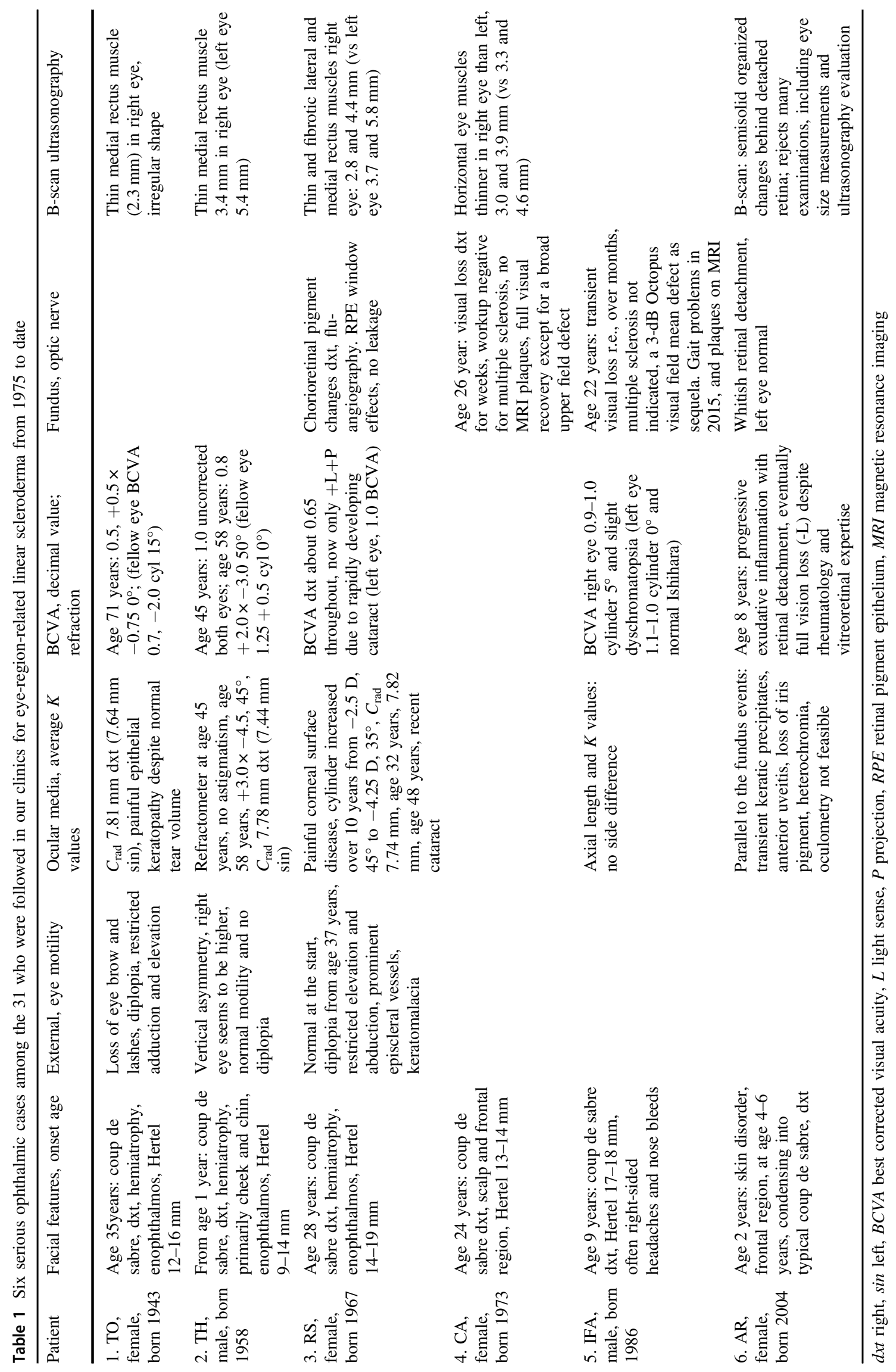


One male patient had deuteranomaly (inherited) when tested on Ishihara plates. Otherwise, there was no evidence of dyschromatopsy or affected contrast sensitivity in the eyes that could see.

\section{Visual fields}

Visual fields had a normal smooth outline for the two standard Goldmann objects, and symmetrical, bilateral, slight marginal restriction in a few cases was considered constitutional. The two patients who had ipsilateral transient visual loss after episodes reminiscent of optic neuritis (Table 1) were exceptions. The episode left the female (patient 4) with findings in the peripheral upper quadrant; Octopus static perimetry demonstrated general sensitivity loss of a few decibels in the male patient (patient 5). In 2015, he acquired gait problems and plaque-like dots on magnetic resonance imaging, suggesting multiple sclerosis as the basic disorder.

\section{Eye size and axial length}

The female with excessive myopia presented axial lengths of 30 and $29 \mathrm{~mm}$. Otherwise, axial eye size ranged from 20.54 to $25.11 \mathrm{~mm}$, with only eight eyes scoring outside the range of 22-24 mm (Table 2). For A/H features, 13 of 27 had a difference exceeding $0.25 \mathrm{~mm}(0.28-1.11 \mathrm{~mm}$; median difference, $0.46 \mathrm{~mm}$ ), with the affected side showing the lower figure in 12, and only 1 with opposite sign $(p<0.01$; sign test). A $t$-test on individual side differences further confirmed that the size of the ipsilateral eye lagged behind slightly (Table 2).

\section{Keratometry, radius of the corneal curvature}

All curvatures were within the physiologic range with a $C_{\text {rad }}$ range of $7.23-8.16 \mathrm{~mm}$ (median, $7.73 \mathrm{~mm}$; mean, 7.69 $\mathrm{mm})$. Low order asymmetry showed no dependence on $\mathrm{A} / \mathrm{H}$ status (Table 2), and side differences less than $0.1 \mathrm{~mm}$ could generally be ascribed to the measuring method. The two cases with acquired coup-related astigmatism (patients 2 and 3, Table 1), however, had a significantly flatter cornea in the affected eye (7.81 vs $7.64 \mathrm{~mm}$ and 7.78 vs. $7.44 \mathrm{~mm}$, respectively). The numerical $\mathrm{A} / \mathrm{H} C_{\mathrm{rad}}$ difference had the same (positive) sign in patient 1, although without an ipsilateral cylinder value associated. A more peaked cornea was recorded in the male who showed a unilateral couprelated astigmatism of 1.75 cylinder (average curvature radius $\mathrm{A} / \mathrm{H}$ values, 7.55 and $7.68 \mathrm{~mm}$, respectively).

\section{Hertel exophthalmometry}

The range on Hertel exophthalometry was $11-20 \mathrm{~mm}$ (median value, $15 \mathrm{~mm}$ ). There was a mean $\mathrm{A} / \mathrm{H}$ difference of $-1.75 \mathrm{~mm}$. The median value was $-1 \mathrm{~mm}$, and the range was from -8 to $1 \mathrm{~mm}$ ). Twelve patients had identical recordings on both sides, and the low median value may be regarded as within measurement error. However, only 1 of the 28 eye pairs with valid measurements had a factual $\mathrm{A} / \mathrm{H}$ difference with a positive sign. The prevailing negative sign for $\mathrm{A} / \mathrm{H}$ also held for those who presented an unambiguous
Table 2 Dimensional parameters (in mm: axial eye length, $C_{\text {rad }}=$ corneal curvature radius, Hertel exophthalmometry, lateral and medial rectus muscle thickness) with number of valid data sets

\begin{tabular}{|c|c|c|c|c|c|}
\hline & & Number & Median (range) & Mean value (SD) & $p$ \\
\hline \multirow[t]{3}{*}{ Ax length $(\mathrm{mm})$} & A & 30 & $22.98(20.5-30.1)$ & $23.03(1.70)$ & \\
\hline & $\mathrm{H}$ & 30 & $23.01(21-29)$ & $23.26(1.46)$ & \\
\hline & $\mathrm{A}-\mathrm{H}$ & 30 & $-0.085(-1.11$ to 1.1$)$ & $-0.23(0.48)$ & 0.01 \\
\hline \multirow[t]{3}{*}{$C_{\mathrm{rad}}(\mathrm{mm})$} & A & 30 & $7.69(7.23-8.12)$ & $7.68(0.25)$ & \\
\hline & $\mathrm{H}$ & 30 & $7.67(7.24-8.16)$ & $7.69(0.26)$ & \\
\hline & $\mathrm{A}-\mathrm{H}$ & 29 & $0(-0.13$ to 0.3$)$ & $0.01(0.08)$ & n.s. \\
\hline \multirow[t]{3}{*}{ Hertel (mm) } & A & 29 & $14(9-20)$ & $14.28(2.62)$ & \\
\hline & $\mathrm{H}$ & 28 & $16(12-20)$ & $16.1(2.40)$ & \\
\hline & $\mathrm{A}-\mathrm{H}$ & 28 & $-1(-8$ to 1$)$ & $-1.75(2.27)$ & $<0.001$ \\
\hline \multirow[t]{3}{*}{ Lat. rect. (mm) } & A & 26 & $2.97(2.0-4.81)$ & $3.24(0.69)$ & \\
\hline & $\mathrm{H}$ & 27 & $3.42(2.3-5.53)$ & $3.52(0.66)$ & \\
\hline & $\mathrm{A}-\mathrm{H}$ & 26 & $-0.24(-1.39$ to 0.9$)$ & $-0.27(0.61)$ & 0.049 \\
\hline \multirow[t]{3}{*}{ Med. rect.(mm) } & A & 27 & $4.27(3.17-5.42)$ & $4.29(0.58)$ & \\
\hline & $\mathrm{H}$ & 28 & $4.85(3.17-6.38)$ & $4.79(0.83)$ & \\
\hline & $\mathrm{A}-\mathrm{H}$ & 27 & $-0.35(-2.9$ to 1.38$)$ & $0.52(1.09)$ & 0.029 \\
\hline
\end{tabular}

Median values and range are presented, as also mean value and standard deviation. Paired comparison of affected (by coup de sabre, ipsilateral, A) vs. healthy (contralateral, H) by Wilcoxon matched pairs test. The calculated individual A minus $\mathrm{H}$ parameter by $t$-test, as differing from zero, all in agreement with the nonparametric Wilcoxon 

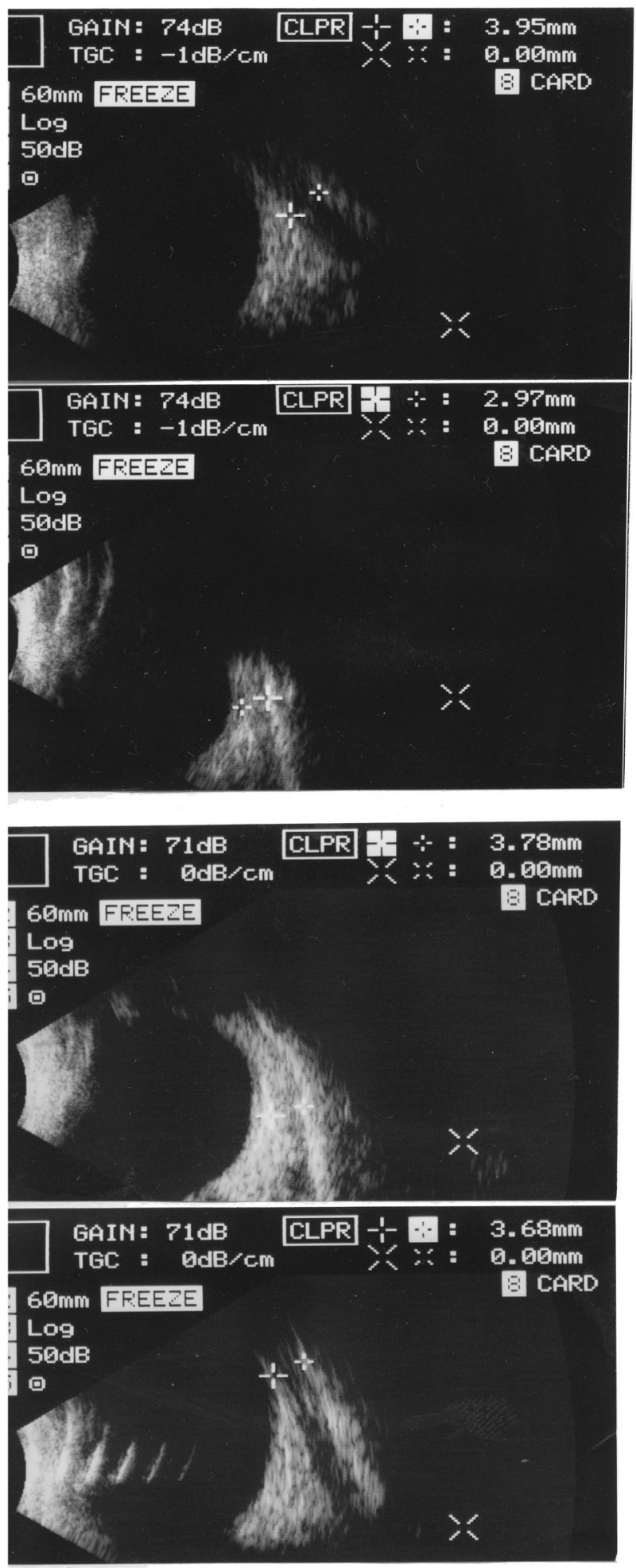

Fig. 2 Transbulbar left eye ultrasonic B-scans in two adult women. Between caliper marks, the band-like shape of the rectus muscles. In frames 1 and 2, the medial and lateral rectus in the first case; in frames 3 and 4 the second case, with the two muscles in the opposite order. The mainly black area in frames 1 and 4 denotes atrophy

side difference $(2-8 \mathrm{~mm} ; n=11)$, and significance was statistically confirmed (Table $2 ; p<0.001 ;$ sign test).
Thus, the final interpretation is either less development on the affected side or eventual loss of orbital tissue volume.

Subdividing the series by onset age 15 years, both axial eye length and exophthalmometry recordings, had shown no dependence $\left(\chi^{2}\right)$ on age of onset of the skin disorder.

\section{Ultrasonically evaluated horizontal external eye muscle thickness}

B-scan ultrasonography did not indicate changes in the sonic texture of orbital tissue, except in three cases where the rectus muscles appeared thin and fibrotic (Fig. 2). The caliper-based method is described in previous articles [16, 17]. For the $\mathrm{A} / \mathrm{H}$ features, both horizontal rectus eyes appeared thinner on the ipsilateral side, however with large excursions, probably partly methodological, though with marginal statistical confirmation (Table 2).

\section{Ophthalmoscopy}

A normal fundus was described in all except patients 3 and 6 (Table 1). The former patient demonstrated discreet asymptomatic ipsilateral pigment losses and mid- to latephase hyperfluorescence on flu-angiography. At the end of 2014, a rapidly developing dense cataract reduced vision to light sense only $(+\mathrm{L})$, but ultrasonography indicated no other lesions. Cataract surgery is supposed to restore good vision, but so far she is relieved of her distressing diplopia caused by the restricted eye motility. Further localized scleromalacia is acknowledged, as suggested by translucent dark uveal spots in the sclera. Patient 6 developed ipsilateral exudative retinal detachment in childhood with full loss of vision.

The optic discs were normal in all patients with clear media. The maximum cup/disc ratio was $0.3 ; 12$ of the 19 patients with optic disc data had no cup recorded, also called small disc at risk (for vascular disorders). We observed no individual asymmetry according to the location of the scleroderma.

\section{The six patients with scleroderma-related ophthalmic events, listed according to age in Table 1}

Ophthalmic functions were eventually affected and deteriorated further in the six patients summarized in Table 1. A deep-set eye as a result of loss of orbital tissue volume was seen in all six. Diplopia caused by restricted eye motility was recorded in two patients (1 and 3 ); the latter also acquired severe ipsilateral visual loss as a result of cataract. Irreversible total ipsilateral visual loss occurred in patient 6, a girl with treatment-resistant intraocular inflammation 
(despite systemic immune suppression and focal laser therapy) and anisocoria was regarded post-uveitic. As already mentioned, fully and partly reversible visual loss on the basis of optic nerve disorder was observed in patients 4 and 5. Changes in corneal form were noted in patients $1-3$, but slit-lamp evaluation did not disclose opacities or other lesions of the cornea.

\section{Discussion}

The limited literature on ECS and ophthalmic complications probably reflects clinical experience. In large collective series of linear scleroderma, ophthalmic complications seem to occur in a maximum of $2-3 \%$ of cases, and as minor findings. In particular, this holds for lids and lashes (symptom-free, and not further discussed here), as also for silent uveitis and prominent episcleral vessels. In selected studies, however, up to $14 \%$ of patients with ECS had ophthalmic findings reported, when analysed as a separate subgroup [18-20]. In general, this supports that eye function remains largely unaffected despite the immediate vicinity of significant trophic pathology. Visual and oculomotor functions are usually intact, even when the ocular adnexa and the eye appear contiguous with the primary soft tissue changes in the skin. Occasional reports of central nervous system involvement should be mentioned in relation to our two cases reminding of optic neuritis, topically representing an anatomic borderline between the orbit and the brain $[13-15,20]$.

With regard to destructive retinal manifestations, Gass et al. [21]. described two children and two young adults with severe visual loss as a result of exudative Coats-like retinal detachment and/or stellate neuroretinopathy [22]. There are reports on diplopia as a result of extra-ocular eye muscle involvement and of ocular inflammation (episcleritis, uveitis, retinitis) $[1,4-7,17,20,21]$. Oculomotor disturbances occurred in 11 cases of facial hemiatrophy, but it is noteworthy that visual acuity was normal in the series, and only one patient had typical ECS [21].

\section{General considerations}

In our series, the dermatological concept of a sable cut after a more or (often) less obvious early inflammatory phase, including initial discoloration of skin, was the main entrance criterion, although with hemiatrophic features in 9 of the 31 patients. Consistent with experience from prototype cases of ECS, most of the patients $(n=24)$ in our series did not present visual or motor deficits, and binocularity was preserved. Typically, slow initial cutaneous disease activity lasted for 3-5 years, and the patients were mainly left with only the vertical furrows that qualified them for inclusion. No significant development or episodes of cutaneous re-activation were observed subsequently.

The most severely affected patients in this cohort are specified in Table 1. They all presented definite and serious ophthalmic events over time (effects on the eye muscles and orbital tissue volume; transient optic nerve involvement; ocular surface disease and cataract; changes in corneal curvature; severe intraocular inflammation with monocular loss of vision). Patient 6 with ECS onset years prior to the inflammation is in line with the exceptional retinal reports of Gass et al. [21].

We found no valid cross-references to multiple sclerosis or to optic neuritis in the literature [23]. A PubMed search was negative, except for a recent report of two childhood cases that mimicked acquired demyelinating disorder [15]. A boy with imaging evidence of cerebral and ocular vasculitis might further suggest a systemic link to involvement of the central nervous system [14]. Summing up, the eventual total of 8 significantly affected patients out of 31 (26\%) seems to mark our otherwise unselected ECS follow-up series as the ophthalmically most affected so far, both in percentage and severity. The severity of the lesions would likely have resulted in detection also in studies less dedicated to eye-related findings, but specific ophthalmic attention in our series is an obvious added possibility.

\section{Corneal curvature and axial eye length. Deviations of growth}

We found an indication of a shorter eye ipsilaterally, and occasionally also a flatter cornea. The latter, in particular, is interesting because definitive anterior eye segment parameters are established during the first years of life, and usually with symmetrical and permanent findings. Side differences associated with linear scleroderma of much later onset therefore indicate some eventual impact on the corneal surface ectoderm. Alternatively, traits of the two pathologies hypothetically might relate to shared genetic factors [5, 24-26].

From birth, axial eye length shows a longer evolution than corneal curvature, until the teens at least, although with myopia as a confounder. There is also greater variability. Thus, occasional side differences are not uncommon, sometimes with anisometropia and risk of amblyopia [2729], as evident in a few of our patients. In the present series, however, the more general $\mathrm{A} / \mathrm{H}$ suggestion of ipsilateral eyes being (or having become) a little shorter seems to be new knowledge. In general, it is not likely that fully grown eyes reduce/alter in size unless with obvious pathology. Furthermore, the not uncommon loss of orbital tissue, irrespective of age, may serve as a possible morphometric parallel. Our findings indicate that patients with ECS 
affecting the orbital region need to be examined routinely by an ophthalmologist [30].

\section{Orbital tissue and external eye muscles}

The loss of volume expressed by relative enophthalmos seems related to fibroblast activity and shrinkage of orbital fat tissue. Regarding trophic $\mathrm{A} / \mathrm{H}$ involvement of the external eye muscles, we should be cautious; so far the significant suggestion of thinner ipsilateral muscles is considered marginal. The ultrasonography technique is approximate, and examiner experience (all measurements in this study were performed by HCF; Fig. 2) is essential for measurements from frozen B-scans considered representative of the parabulbar horizontal recti muscles [23, 24, 31]. We abstained from evaluating the vertical and oblique muscles, where exact imaging seems more complex, because of the even greater difficulty in securing the sound beam perpendicular to the muscle(s). Another issue of interest is the long-term functional adaptation to eye muscle and orbital volume involvement that is reflected by preserved motility and binocularity in almost all cases.

\section{Conclusions}

Our extended search for gross ophthalmic findings resulted in 10 definite ipsilateral ophthalmic pathologies, in 8 of the 31 patients $(26 \%)$, which makes it the most severely ophthalmically affected group of ECS patients published so far. This is probably the result of the targeted ophthalmic approach, in contrast to the more occasional and often minor observations reported in the literature. Ultrasound oculometry indicated smaller size (eye and orbital structures), even when the linear scleroderma had its clinical onset after adolescent termination of ophthalmic growth. Hypothetical explanations are late-onset directional remodelling or a genetically based dysmorphology with late manifestation. These more subtle indications regarding timing of ocular growth and tissue loss of external eye muscles may further inspire future studies of linear scleroderma and its influence on growth patterns of relevance for facial structures.

\section{Summary}

\section{What was known before}

- Linear scleroderma of the face (en coup de sabre) is a disfiguring chronic skin disorder, often starting in childhood or adolescence.

- According to the literature, involvement of the 'on line' eye is rare, often just minor, and noticed mainly as an occasional finding.

\section{What this study adds}

- In a consecutive long-term series of 31 patients with eye-related ECS attending the Copenhagen University Hospital, we have specified the full ophthalmic status and followed eight serious cases, all with ipsilateral manifestations.

- Added to the prevalent state of enophthalmos and more exceptional function loss, the oculometry data suggest a smaller eye on the diseased side.

\section{Compliance with ethical standards}

Conflict of interest The authors declare that they have no conflict of interest.

\section{References}

1. Tollefsen MM, Witman P. En coup de sabre morphea and Parry Romberg syndrome. A retrospective review of 54 patients. J Acad Dermatol. 2007;56:257-63.

2. Christen-Zaech S, Hakim MD, Afsar FS, Paller AS. Pediatric morphea (localized scleroderma): review of 136 patients. J Am Acad Dermatol. 2008;59:385-96.

3. Peterson LS, Nelson AM, Su WP. Classification of morphea (localized scleroderma). Mayo Clin Proc. 1995;70:1068-76.

4. Segal P, Jablonska S, Mrzyglod S. Ocular changes in linear scleroderma. Am J Ophthalmol. 1961;51:807-13.

5. Serup J, Serup L, Sjö O. Localized scleroderma 'ECS' with external eye muscle involvement at the same line. Clin Exp Dermatol. 1984;9:196-200.

6. Olver J, Laidler P. Acquired Brown's syndrome in a patient with combined lichen sclerosus et atropicus and morphoea. $\mathrm{Br} \mathrm{J}$ Ophthalmol. 1988;72:552-7.

7. Suttorp-Schulten MSA, Korneef L. Linear scleroderma associated with ptosis and motility disorders. $\mathrm{Br} \mathrm{J}$ Ophthalmol. 1990;74:694-5.

8. Ramboer K,Demaerel PH,Baert AL,Casteels I,Gralands G, Linear scleroderma with orbital involvement: follow-up and magnetic resonance imaging. Letter to editor. $\mathrm{Br} \mathrm{J}$ Ophthalmol. 1997;81:931

9. Mauget-Faÿsse M, Maftouhi MQ-E, Ducournau Y, Rousset H. Frontal linear scleroderma (en coup de sabre) associated with central serous chorioretinopathy. Retin Cases Brief Rep. 2007;1:22-4.

10. Chak G, Wang HZ, Feldon SE. Coup de sabre presenting with worsening diplopia and enophthalmos. Ophthal Plast Reconstr Surg. 2011;27:e97-8.

11. Menni S, Marzano AV, Passoni E. Neurologic abnormalities in two patients with facial hemiatrophy and sclerosis coexisting with morphea. Pediatr Dermatol. 1997;14:113-6.

12. Stone J, Franks AJ, Guthric JA, Johnson MH. Scleroderma en coup de sabre: pathological evidence of intracerebral inflammation. J Neurol Neurosurg Psychiatr. 2001;70:382-5.

13. Blaszczyk M, Krölicki L, Krasu M, Glinska O, Jablonska S. Progressive facial hemiatrophy: central nervous system 
involvement and relationship with scleroderma en coup de sabre. J Rheumatol. 2003;30:1997-2004.

14. Holl-Wieden A, Klink T, Klink J, Warmuth-Metz M, Girschick HJ. Linear scleroderma 'en coup de sabre' associated with cerebral and ocular vasculitis. Scand J Rheumatol. 2006;35:401-4.

15. Kraus V, Lawson EF, von Scheven E, Tihan T, Garza J, Nathan RG, et al. Atypical cases of scleroderma en coup de sabre. J Child Neurol. 2014;29:698-703.

16. Fledelius HC, Zimmermann-Belsing $\mathrm{T}$, Feldt-Rasmussen $\mathrm{U}$. Ultrasonically measured horizontal eye muscle thickness in thyroid associated orbitopathy: cross-sectional and longitudinal aspects in a Danish series. Acta Ophthalmol. 2003;81: $143-50$.

17. Zimmmermann-Belsing T, Feldt-Rasmussen U, Fledelius HC. Ultrasonically measured eye muscle thickness in thyroid disease. Is orbital involvement associated with thyroid auto-antibodies. Eur J Ophthalmol. 2003;12:351-8.

18. Marzano AV,Menni S,Parodi SA,Borghi A,Fulligni A,Fabbri P, et al.Localized scleroderma in adult and children. Clinical and laboratory investigations on 239 cases. Eur J Dermatol. 2003;13:171-6.

19. Zulian F, Vallongo C, Woo P, Russo R, Ruperto N, Harper J, et al. Localized scleroderma in childhood is not just a skin disease. Arthritis Rheum. 2005;52:2873-81.

20. Zannin ME, Martini G, Athreya BH, Russo R, Higgins GC, Vittadello $\mathrm{F}$, et al. Ocular involvement in children with localised scleroderma: a multi-centre study. Br J Ophthalmol. 2007; 91:1311-4
21. Gass JDM, Harbin TS, DelPiereo EJ. Exudative stellate neuroretinopathy and $\mathrm{Cao}$ in patients with progressive hemifacial atrophy. Eur J Opthalmol. 1991;1:2-10.

22. Lindemann HO. Interessante Befunde bei Hemiatrophia facilias progressive. Albrecht Von Graefes Arch Klin. 1940;140:409-38.

23. Miller NR, editor. True localizing symptoms and signs of tumors. In: Walsh \& Hoyt's Clinical Neuro-ophthalmology. 4th edn. Vol. 3. Baltimore, MD: Williams \& Wilkins; 1988. p. 1142-6.

24. Serup J, Alsbirk PH. Localized scleroderma 'en coup de sabre' and iridopalpebral atrophy at the same line. Acta Derm Venereol. 1983;63:75-77.

25. Shmidt B, Guberina C. Coloboma in progressive hemifacial atrophy. Am J Ophthalmol. 1977;84:85-89.

26. Weibel L, Harper JI. Linear morphoea following Blascko's lines. Br J Dermatol. 2008;159:175-81.

27. Fledelius HC. Refractive components in aniso- and isometropia. An oculometric study. Docum Ophthal Proc Ser. 1981;28:89-95.

28. Fledelius HC. Is myopia getting more frequent? A cross-sectional study of 1416 adult Danes. Acta Ophthalmol. 1983;61:545-59.

29. Fledelius HC, Christensen AS, Fledelius C. Juvenile eye growth, when completed? An evaluation based on IOL-Master data, crosssectional and longitudinal. Acta Ophthalmol. 2014;92:259-64.

30. Fledelius HC. $F \times \lambda=v$. Dimensions in ophthalmology. Jules Francois Memorial Lecture SIDUO XXV Berlin 2014. Enliven Pediatr Neonatal Biol. 2015;2(3):006 in press.

31. Muschnik RS, Aston SJ, Rees TD. Ocular manifestation and treatment of hemifacial atrophy. Am J Ophthalmol. 1979;88:889-97. 